\title{
Behavioral suites mediate group-level foraging dynamics in communities of tropical stingless bees
}

\author{
E. M. Lichtenberg • V. L. Imperatriz-Fonseca • \\ J. C. Nieh
}

Received: 6 June 2009/Revised: 23 October 2009/Accepted: 24 November 2009/Published online: 18 December 2009

(C) The Author(s) 2009. This article is published with open access at Springerlink.com

\begin{abstract}
Competition for floral resources is a key force shaping pollinator communities, particularly among social bees. The ability of social bees to recruit nestmates for group foraging is hypothesized to be a major factor in their ability to dominate rich resources such as mass-flowering trees. We tested the role of group foraging in attaining dominance by stingless bees, eusocial tropical pollinators that exhibit high diversity in foraging strategies. We provide the first experimental evidence that meliponine group foraging strategies, large colony sizes and aggressive behavior form a suite of traits that enable colonies to improve dominance of rich resources. Using a diverse assemblage of Brazilian stingless bee species and an array of artificial "flowers" that provided a sucrose reward, we compared species' dominance and visitation under unrestricted foraging conditions and with experimental removal of group-foraging species. Dominance does not vary with individual body size, but rather with foraging group size.
\end{abstract}

Electronic supplementary material The online version of this article (doi:10.1007/s00040-009-0055-8) contains supplementary material, which is available to authorized users.

E. M. Lichtenberg $(\bowtie) \cdot$ J. C. Nieh

Division of Biological Sciences, University of California

San Diego, 9500 Gilman Drive \#0116,

La Jolla, CA 92093-0116, USA

e-mail: elichten@ucsd.edu

J. C. Nieh

e-mail: jnieh@ucsd.edu

\section{L. Imperatriz-Fonseca}

Departamento de Biologia, Faculdade de Filosofia, Ciéncias e Letras de Ribeirão Preto, Universidade de São Paulo, Av. Bandeirantes 3900, Monte Alegre, 14040-901 Ribeirão Preto, SP, Brazil

e-mail: vlifonse@ib.usp.br
Species that recruit larger numbers of nestmates (Scaptotrigona aff. depilis, Trigona hyalinata, Trigona spinipes) dominated both numerically (high local abundance) and behaviorally (controlling feeders). Removal of groupforaging species increased feeding opportunities for solitary foragers (Frieseomelitta varia, Melipona quadrifasciata and Nannotrigona testaceicornis). Trigona hyalinata always dominated under unrestricted conditions. When this species was removed, $T$. spinipes or $S$. aff. depilis controlled feeders and limited visitation by solitary-foraging species. Because bee foraging patterns determine plant pollination success, understanding the forces that shape these patterns is crucial to ensuring pollination of both crops and natural areas in the face of current pollinator declines.

Keywords Aggression - Dominance - Group foraging · Species removal $\cdot$ Superorganism

\section{Introduction}

The availability of rich resources such as mass-flowering trees is important in shaping foraging behavior of tropical pollinators (Roubik, 1989; Wilms et al., 1996). Such resources attract a high diversity of visitors (Heithaus, 1979), and can be fiercely contested (Roubik, 1980; Nagamitsu and Inoue, 1997). Foraging shifts resulting from competitive interactions (e.g. Inouye, 1978) may alter pollination dynamics (Roubik and Villanueva-Gutiérrez, 2009). For social insects, intense inter- and intraspecific competition (Johnson and Hubbell, 1974; Hölldobler and Wilson, 1990; Dornhaus and Chittka, 2004) should favor strategies such as cooperative group foraging that improve foraging efficiency and resource defense. Group foragers are those who forage in the same location as nestmates. 
They often use information provided by group members to locate food sources.

When animals compete for food, larger species tend to dominate (Schoener, 1983; Eccard and Ylönen, 2003) in both direct (e.g. interference competition) and indirect (e.g. exploitative competition) contests. For social animals, however, foraging in groups can improve yield through shared food location information (Clark and Mangel, 1984), increased hunting success (Bednarz, 1988), retrieval of larger food items (Traniello and Beshers, 1991), control of food (Holway and Case, 2001) or more efficient harvesting (Fernández-Juricic et al., 2004). Group foraging may be particularly important for highly social insects whose colonies act as "superorganisms" (Wilson, 1990), reproductive units whose parts, individuals, must work together to permit colony survival and reproduction. Thus, superorganism size (group size) may be more relevant than individual size for determining the outcome of dominance interactions.

Stingless bees (Hymenoptera, Apidae, Meliponini) provide a good system for studying the ecological importance of group foraging. All stingless bees are eusocial, but some species forage as individuals while others tend to forage in large groups (Johnson, 1983). These groups typically form through location-specific recruitment via odor trails or potentially referential vibrations (Nieh, 2004). Foraging strategies are likely constrained by colony sizes, which range from approx. 100 (van Veen et al., 1997) to at least 20,000 workers (Roubik, 1983). Stingless bee within-habitat diversity can range up to 62 species (Roubik, 1989) with considerable diet overlap (e.g. Wilms and Wiechers, 1997; Eltz et al., 2001). Limited food availability (Hubbell and Johnson, 1977; Eltz et al., 2002) can thus lead to high levels of both intra- and interspecific competition (Hubbell and Johnson, 1977; Nagamitsu and Inoue, 1997; Slaa, 2003).

Despite these bees' important role as tropical pollinators (Heard, 1999), the ecological importance of stingless bee foraging strategies remains poorly understood. Several researchers have hypothesized that group foraging improves dominance for stingless bees (Johnson and Hubbell, 1975; Roubik, 1980; Nagamitsu and Inoue, 1997; Slaa, 2003). However, there are few tests of these hypotheses and no studies directly manipulate dominance by altering experimental conditions (e.g. species removal). In addition, most studies of stingless bee foraging behavior have focused primarily on aggression, comparing resource control of "aggressive" versus "unaggressive" species (Biesmeijer and Slaa, 2004 and sources therein). While aggression is a commonly proposed mechanism of interference competition (Reitz and Trumble, 2002), other traits also permit species to control or efficiently exploit a resource. For example, the stingless bee Partamona orizabaensis (formerly P. aff. cupira, Pedro and Camargo, 2003) is "non-aggressive" (Biesmeijer and Slaa, 2004) yet in large groups can maintain control of a resource despite attack by Trigona silvestriana (Howard, 1985).

We experimentally altered an assemblage of stingless bees foraging at an array of feeders to investigate stingless bee dominance and foraging on a resource accessible to multiple species. We measured behavioral dominance, numerical dominance, displacement success and aggression of six Brazilian species. We tested three hypotheses: (H1) group foragers are dominant, as is found for other social insects; (H2) body size correlates with dominance (Johnson and Hubbell, 1974); and (H3) removal of groupforaging species increases feeding opportunities for remaining species. Finally, we examined the role of aggression in resource dominance.

\section{Methods}

Study site and species, and feeder array

This study was carried out at the Fazenda Aretuzina, a ranch in the state of São Paulo, Brazil, during July of 2006. This area is home to at least 12 native stingless bee species (P. Nogueira-Neto, pers. comm.). Colonies of several species were also kept in hives at the Fazenda.

We selected six species that span a broad range of foraging strategies, colony sizes, body sizes and aggression levels (based on similarity with congeners described by Biesmeijer and Slaa, 2004). These species also show overlap in plant species utilization (Table S1 in Electronic Supplementary Material): Frieseomelitta varia (Lepeletier, 1836), Melipona quadrifasciata Lepeletier 1836, Nannotrigona testaceicornis (Lepeletier, 1836), Scaptotrigona aff. depilis, Trigona hyalinata (Lepeletier, 1836), and Trigona spinipes (Fabricius, 1793). Trigona species were from wild colonies, each estimated to be $200-400 \mathrm{~m}$ from the feeder array and in opposite directions (Fig. S1 in Electronic Supplementary Material). The other four species occupied nest boxes dispersed in a meliponary occupying approximately $1 \mathrm{ha}$, at a density similar to that found under natural conditions (Antonini and Martins, 2003). We trained one colony of each species (von Frisch, 1967) to an artificial feeder array approximately $50 \mathrm{~m}$ from the center of the meliponary. Table 1 lists characteristics of the study species. Head widths were measured for 38-40 individuals (two to four colonies) of each species using a Leica M16 microscope with Leica camera attachment (model DFC500). Colony size estimates are based on reliable published data. We used descriptions of bees foraging on natural food sources to characterize foraging strategies, based on a functional definition that considers numbers of 
Table 1 Characteristics of bee species studied

\begin{tabular}{|c|c|c|c|c|c|}
\hline Species & $\begin{array}{l}\text { Head width } \\
(\mathrm{mm})\end{array}$ & $\begin{array}{l}\text { Average colony size } \\
\text { (\# workers) }\end{array}$ & $\begin{array}{l}\text { Recruitment } \\
\text { mechanism }\end{array}$ & Group forager? & $\begin{array}{l}\text { Estimated flight } \\
\text { range }(\mathrm{m})\end{array}$ \\
\hline F. varia & $2.33 \pm 0.06$ & $\begin{array}{l}875 \text { (Tóth et al., 2004; } \\
\text { Nunes et al., 2008) }\end{array}$ & SA? & No (Jarau et al., 2003) & 705 \\
\hline M. quadrifasciata & $3.89 \pm 0.11$ & $\begin{array}{l}715 \text { (Roubik, 1980; } \\
\text { Wille and Michener, } \\
\text { 1973; Tóth et al., 2004) }\end{array}$ & $\begin{array}{l}\text { SM (Lichtenberg et al., } \\
\text { 2009), 3-DS? }\end{array}$ & No (Kerr, 1994) & $\begin{array}{l}2000 \text { (Kerr, } \\
1996)\end{array}$ \\
\hline N. testaceicornis & $1.90 \pm 0.03$ & $\begin{array}{l}\text { 1,750 (Lindauer and Kerr, } \\
\text { 1960; Jarau et al., 2003) }\end{array}$ & $\begin{array}{l}\text { SM (Schmidt et al., } \\
\text { 2005) }\end{array}$ & $\begin{array}{l}\text { No (Jarau et al., } \\
\text { 2003) }\end{array}$ & 468 \\
\hline S. aff. depilis & $2.69 \pm 0.04$ & $\begin{array}{l}\text { 6,000 (Ramalho, 1990; } \\
\text { Jarau et al., 2003) }\end{array}$ & $\begin{array}{l}\text { OT (Schmidt } \\
\text { et al., 2003) }\end{array}$ & Yes (Jarau et al., 2003) & 903 \\
\hline T. hyalinata & $2.81 \pm 0.04$ & $\begin{array}{l}\text { 15,000 (D. W. Roubik, } \\
\text { pers. comm.) }\end{array}$ & $\begin{array}{l}\text { OT (Nieh et al., } \\
2003)\end{array}$ & Yes (Roubik, 1980) & 969 \\
\hline T. spinipes & $2.79 \pm 0.05$ & $\begin{array}{l}\text { 5,500 (Wille and } \\
\text { Michener, 1973) }\end{array}$ & $\begin{array}{l}\text { OT (Lindauer and } \\
\text { Kerr, 1960) }\end{array}$ & $\begin{array}{l}\text { Yes (Cortopassi-Laurino } \\
\text { and Ramalho, 1988) }\end{array}$ & $\begin{array}{c}840 \text { (Kerr, 1959, } \\
\text { T. spinipes }= \\
\text { T. ruficrus })\end{array}$ \\
\hline
\end{tabular}

Recruitment mechanisms are: three-dimensional communication of food location without the use of an odor trail (3-DS), odor trail deposited along visually prominent landmarks between the food source and the nest (OT), sounds and agitation inside the nest that do not indicate food source location (SA), and scent marking of the food source (SM). Flight ranges with no citation were estimated from van Nieuwstadt and Ruano Iraheta (1996)

nestmates visiting the same food source rather than on recruitment. Species whose colonies can forage in large groups at the same spatial location were categorized as group foraging. Those whose workers forage as solitary individuals at different spatial patches are solitary foraging. Many group-foraging species will not permit non-nestmate conspecifics to forage in close proximity (Johnson and Hubbell, 1974; pers. obs.), thus large groups of these species are generally foragers from one colony.

Feeders consisted of yellow $1.5 \mathrm{~mL}$ Eppendorf tubes from which four capillary tubes protruded by $1-2 \mathrm{~mm}$ (Figs. 1, S2). Each tube rested in a white nylon washer upon which bees stood when feeding and interacting.

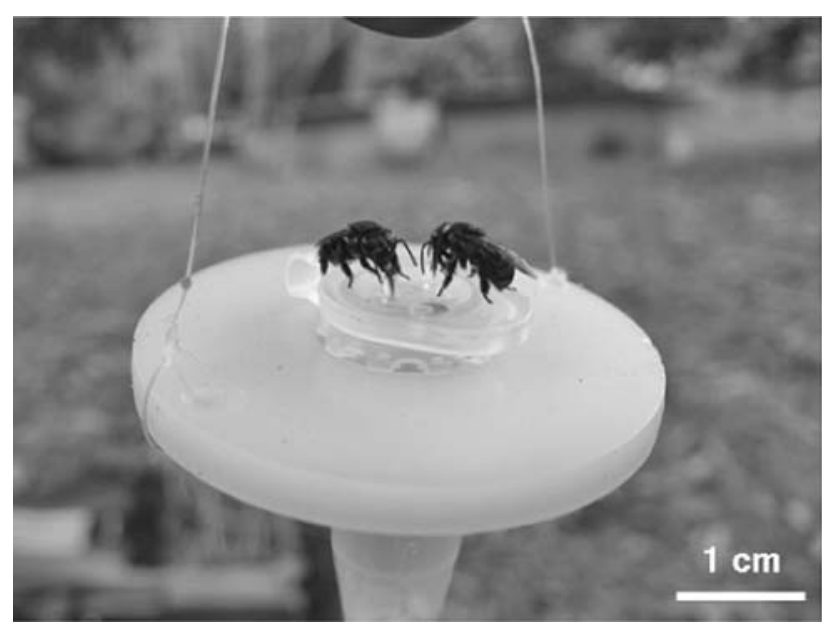

Fig. 1 Artificial "flower" used in this experiment, with two feeding S. aff. depilis foragers
Sixteen feeders were suspended from a $15 \mathrm{~m} \times 15 \mathrm{~m}$ grid, and were spaced every $5 \mathrm{~m}$. This created a resource that was easily exploitable by all study species, despite differences in tongue length and body size. We filled feeders with $2.5 \mathrm{M}$ unscented sucrose solution during training and 1.5 $\mathrm{M}$ unscented sucrose solution during experimentation, providing sucrose ad libitum.

\section{Data collection}

We monitored the feeder array in 5-min periods, observing from 0900 to 1146 (morning trials) or 1300 to 1546 (afternoon trials). Stingless bees show activity peaks at different times of day (Roubik, 1989). Observation during both morning and afternoon thus allowed us to study interactions over a broad time span. We began observation after sunrise because, during austral winter, chilly early morning temperatures delay foraging activity of many stingless bee species (Hilário et al., 2000). During nonremoval trials (see below), each of four observers rotated among four feeders, moving sequentially down a row and then returning to the beginning of that same row. Movement between feeders occurred during 1-min pauses between observation periods.

To assess interspecific effects on foraging, we used aspirators to remove group-foraging species from feeders. We removed (1) $T$. hyalinata, (2) $T$. hyalinata and $T$. spinipes, (3) T. hyalinata and S. aff. depilis or (4) T. hyalinata, $T$. spinipes and $S$. aff. depilis. In all trials, we removed $T$. hyalinata because this species dominated the entire feeder array whenever it was present. For each removal combination and for the non-removal treatment, 
we conducted one morning and one afternoon trial. Aspirated bees were released away from the feeder array at the end of each trial. Because removal requires constant attention to feeders, we used four feeders (one per observer) during removal trials. Observers did not move during the removal trials, but continued to implement the 1-min pause between 5-min observation periods. Observer row assignments and feeder positions within each row were randomly assigned. Non-removal and removal trials were interspersed with each other, and with several days during which data were not collected, across 10 days.

Each observer recorded the species visiting the focal feeder and all interspecific interactions. Feeders were also videotaped during observation periods, and bee interactions were verified from the video. We did not individually mark all bees because doing so would have disrupted recruits and altered results. Thus, we recorded the maximum number of bees simultaneously feeding during each period for each species rather than the total number of visits.

For each interspecific interaction that occurred during an observation period, we recorded (1) species identity and number of individuals, (2) interaction initiator, (3) interaction outcome and (4) intensity of aggression. Displacement was considered aggressive when one individual directed movement toward another bee that could cause injury (e.g. spreading mandibles or biting), or that potentially increased the aggressor's apparent size (e.g. wing or leg spreading). We defined non-aggressive displacement as the rapid departure of a bee when another bee arrived but showed no evident aggression. An individual won an interaction if her opponent moved away immediately after the encounter.

\section{Data analysis}

We calculated three measures of dominance and one index of aggression for each species. (1) Behavioral dominance indicates a colony's ability to control a resource. We determined the number of turnovers in favor of each species, a turnover being defined as a change in the species makes up at least $50 \%$ of individuals at a feeder. Behavioral dominance was weighted to adjust for the number of trials each species was present at the array. (2) We use numerical dominance to indicate local abundance at the array. For each trial, we determined the largest number of bees visiting the array during a single observation period. Behavioral and numerical dominance were calculated separately for non-removal and removal trials. (3) For each species, we calculated displacement success-the ability to win fights-as the proportion of displacement interactions (aggressive and non-aggressive) won during non-removal trials. This measure is comparable to "dominance" of species where contests occur between individuals rather than groups (e.g. Dingemanse and de Goede, 2004; White et al., 2007). (4) Attack probability is the number of aggressive displacement interactions that each species initiated as a proportion of the total number of such interactions in which it was involved (Catlett, 1961). To more accurately represent species aggression, attack probability includes interactions from all trials. Due to the non-parametric nature of several indices and the fact that we compare species rather than individuals, we are sometimes limited to describing the effects of removal rather than using statistical tests. Analyses were conducted in R v. 2.8.1 (R Development Core Team, 2008).

\section{Results}

\section{Species dominance patterns}

Table 2 shows dominance values and ranks in non-removal trials for each species. Trigona hyalinata was clearly the dominant species, both behaviorally and numerically. All feeders were completely controlled by Trigona hyalinata at the end of each non-removal trial. Scaptotrigona aff. depilis and $T$. spinipes occasionally behaviorally dominated individual feeders before expulsion by $T$. hyalinata, but the remaining three species never did. Scaptotrigona aff. depilis was relatively abundant at the feeder array, maintaining on average a maximum of 11 bees/trial. The remaining species averaged between 0.5 and 3 bees/trial.

As predicted by $\mathrm{H} 1$, group-foraging species, which had larger colonies (Table 1), ranked above solitary-foraging
Table 2 Dominance and aggressive index values (and ranks) calculated for each species

Behavioral and numerical dominance values are for nonremoval trials

\begin{tabular}{lccll}
\hline Species & $\begin{array}{l}\text { Behavioral } \\
\text { dominance }\end{array}$ & $\begin{array}{l}\text { Numerical } \\
\text { dominance }\end{array}$ & $\begin{array}{l}\text { Displacement } \\
\text { success }\end{array}$ & $\begin{array}{l}\text { Attack } \\
\text { probability }\end{array}$ \\
\hline F. varia & $0.00(5)$ & $2.50(4)$ & $0.300(4)$ & $0.26(5)$ \\
M. quadrifasciata & $0.00(5)$ & $2.00(5)$ & $0.000(5.5)$ & $0.06(6)$ \\
N. testaceicornis & $0.00(5)$ & $0.50(6)$ & $0.000(5.5)$ & $0.30(4)$ \\
S. aff. depilis & $1.00(2)$ & $11.00(2)$ & $0.303(3)$ & $0.80(3)$ \\
T. hyalinata & $11.50(1)$ & $22.50(1)$ & $0.737(1)$ & $0.86(2)$ \\
$T$. spinipes & $0.50(3)$ & $3.00(3)$ & $0.332(2)$ & $0.89(1)$ \\
\hline
\end{tabular}


species in all three dominance measures (Fig. 2a). Because stingless bee nest sizes are better known than foraging behavior, we also determined the relationship between dominance and colony size (Fig. 2b). Species with larger colonies were behaviorally dominant $(r=0.94, N=6$, $P=0.005)$ but only marginally more abundant at the feeder array ( $r=0.83, N=6, P=0.06$ ). Contrary to $\mathrm{H} 2$, body size did not correlate with either behavioral (Fig. 2c;
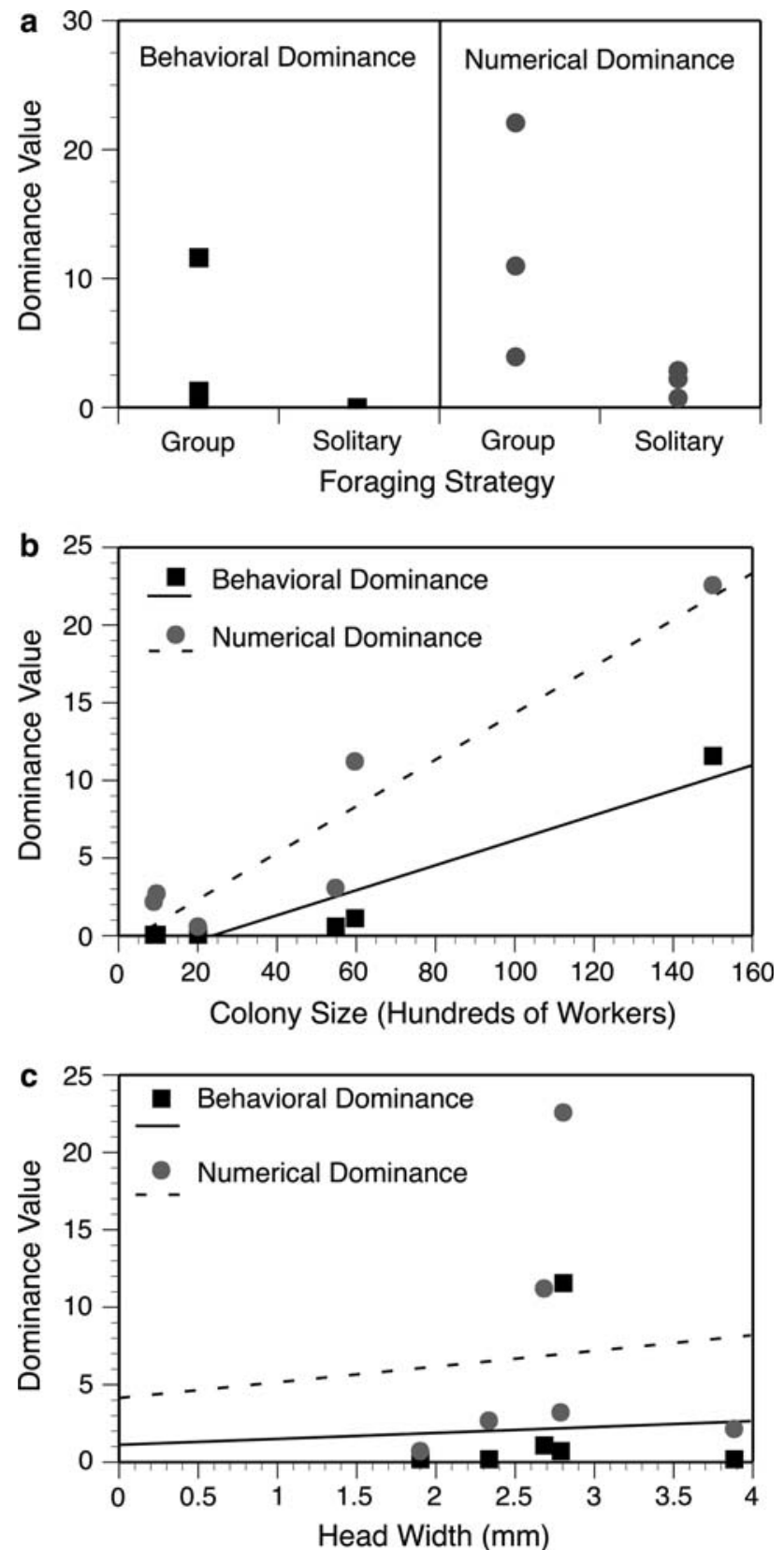

Fig. 2 a Group foragers show higher behavioral and numerical dominance than do solitary foragers. b Dominance increases with colony size. Lines were fit using least squares. c Dominance does not reflect body size. See text for statistics $r=0.33, \quad N=6, \quad P=0.52$ ) or numerical (Fig. 2c; $r=0.37, N=6, P=0.50)$ dominance. We found no relationship between colony size and body size $(r=0.03$, $N=6, P=1)$. Probability of winning fights correlated with colony size ( $r=0.84, N=6, P=0.04)$, but not with body size $(r=0.29, N=6, P=0.58)$. Thus, group-foraging species with large colonies $(\mathrm{H} 1)$, but not species with larger worker body size (H2), are dominant.

\section{Effects of species removal}

Removal of group-foraging species increased feeding opportunities for the remaining species, supporting $\mathrm{H} 3$. All species except $N$. testaceicornis increased behavioral dominance during removal trials (Fig. 3a), yielding a more even spread of turnovers across non-removed species. The per-feeder turnover rate, however, was relatively constant across trials, averaging 0.91 turnovers/ feeder without removal and 0.73 turnovers/feeder during removal trials. For all species, numerical dominance increased almost threefold with exclusion of group foragers (Fig. 3b; quasi-Poisson regression: $\chi_{1}^{2}=7.51$, $P=0.006, e^{\mathrm{b}}=2.72$ ). Removing one or two group-foraging species resulted in dominance by a remaining group forager.

Solitary-foraging species are unlikely to show major increases in numerical dominance. Thus, for each treatment we also determined the number of observation periods during which each species fed. This provides a robust measure of species visitation and resource consumption, facilitating comparisons among species with different foraging strategies. All species except $N$. testaceicornis increased visitation in the absence of group foragers (F. varia: $\chi_{4}^{2}=37.01, P<0.0001 ; M$. quadrifasciata: $\chi_{4}^{2}=28.82, P<0.0001 ; N . \quad$ testaceicornis: $\chi_{4}^{2}=8.76$, $P=0.07 ; \quad S . \quad$ aff. depilis: $\chi_{2}^{2}=15.03, \quad P=0.0005$; T. spinipes: $\left.\chi_{2}^{2}=17.78, P=0.0001\right)$. Solitary-foraging species benefited most from complete removal of group foragers, and occasionally were able to increase visitation even in the presence of one group-foraging species (Fig. 3c).

\section{Aggression}

All species showed some degree of aggression. We observed 499 interspecific displacements of which $59 \%$ involved aggression, 94\% were one-on-one and $77 \%$ were initiated by group-foraging species. Group-foraging species were significantly more aggressive than solitary-foraging species (Table 2; Scheffé's test for proportions, $S=9.46$, $P<0.0005$; Zar, 1999). The majority of attacks (75\%) were directed toward M. quadrifasciata (Table S2). Most interactions involved low levels of aggression, with prolonged 

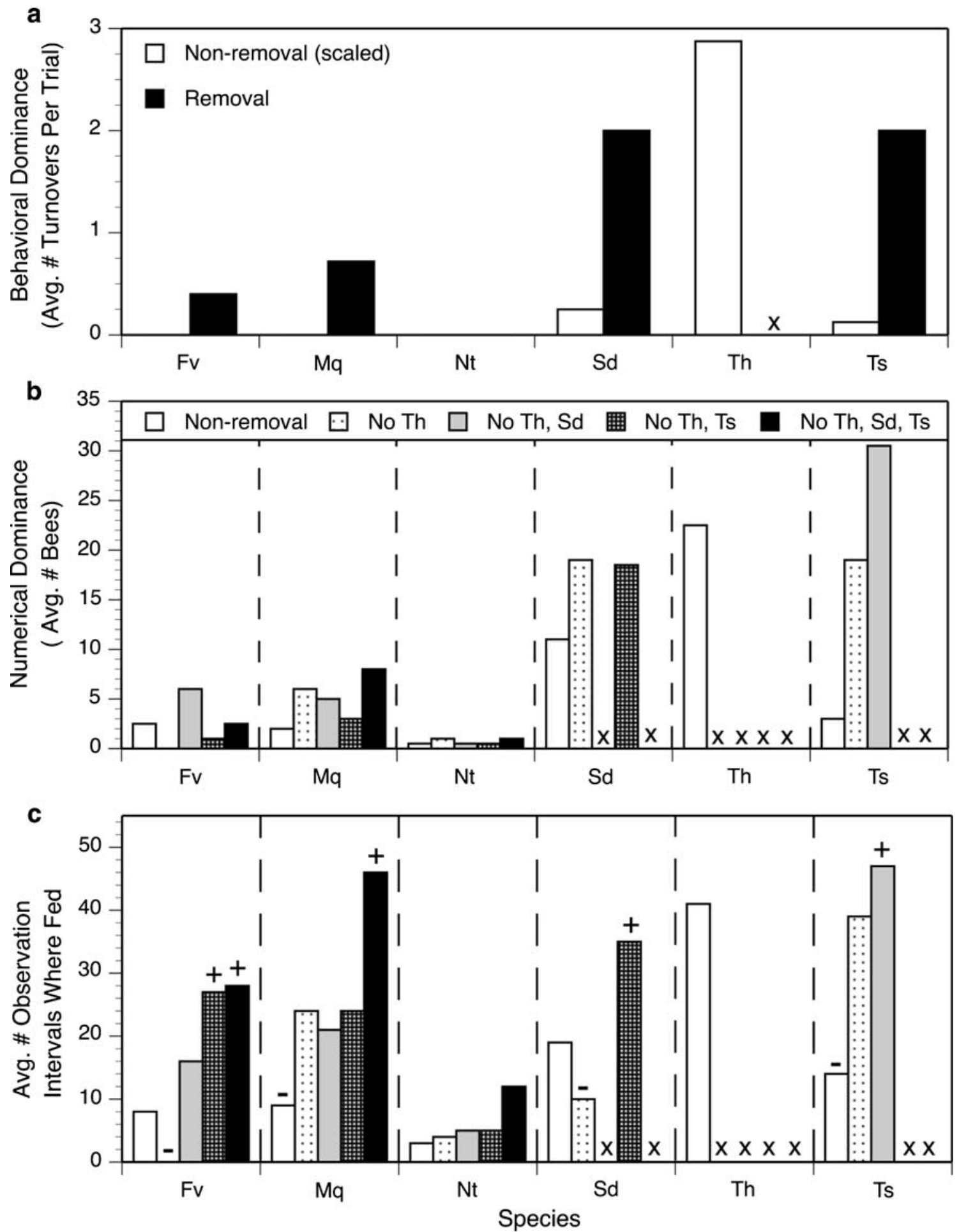

Fig. 3 Fv, Frieseomelitta varia; Mq, Melipona quadrifasciata; Nt Nannotrigona testaceicornis; Sd, Scaptotrigona aff. depilis; Th, Trigona hyalinata; Ts, Trigona spinipes. a Behavioral dominance increases with removal of group-foraging species. Non-removal values are scaled by $1 / 4$ to account for the different numbers of feeders observed

fights occurring only 13 times. Correlations between aggression and dominance were weak at the species level (behavioral dominance: $r=0.76, \quad N=6, \quad P=0.08$; in removal and non-removal trials. b Numerical dominance increases with removal of group-foraging species. A " $x$ " indicates that the species was removed during that treatment. $\mathbf{c}$ Feeder visitation increases with removal of group-foraging species. "+" and " -" indicate standardized residuals $>2$ or $<-2$, respectively. See text for statistics

numerical dominance: $r=0.66, N=6, P=0.18$ ), but stronger at the individual level (displacement success: $r=0.89, N=5, P=0.03)$. 


\section{Discussion}

We show that stingless bee species that form larger colonies and forage in large groups are able to dominate resources, altering the foraging patterns of displaced bees. Our results strongly suggest that, for highly social superorganisms, group size can have the same ecological role as body size does for non-social species. First, group-foraging species were more likely to control a resource and win individual fights than solitary-foraging species (H1). Second, worker body size did not relate to dominance (H2). Third, experimental removal of group foragers increased feeding opportunities for remaining species (H3). Numerical dominance, behavioral dominance and visitation of all species increased during removal trials. The small increases in dominance of solitary foragers after removal of group foragers enabled these colonies to feed for significantly longer. They thus likely collected more of the resource in the absence of group foragers. These experimental results are consistent with observed patterns of bee floral visitation in a Malaysian dipterocarp forest, where non-aggressive species showed increased visitation in the absence of an aggressive, dominant species (Nagamitsu and Inoue, 1997). Group-foraging species showed larger dominance increases with removal than did solitary-foraging species. However, the success of group-foraging species was not due solely to greater abundance. Feeders were often defended by a single Scaptotrigona or Trigona forager. Group forager abundance typically increased only after other species were chased away. Aggression facilitated species turnover and the subsequent increase in aggressor abundance. Our results suggest that group foraging is part of a suite of traits that evolved in several stingless bee genera as a mechanism promoting successful foraging in the face of intense competition, which can occur during times of several floral shortage (Roubik, 1989). These traits include large colonies, rapid locationspecific recruitment via odor trails and aggression at food sources.

Stingless bees have likely evolved multiple strategies to improve competitive success during dearth seasons. Forming a large, aggressive group at the resource ("thuggery") is one strategy. Pronounced mandibular teeth, such as those characteristic of Trigona species (Schwarz, 1948), likely improve fighting ability of "thug" species. Some large Melipona species may use an alternative strategy ("tenacity") by continuing to feed despite being the recipients of aggression. We found a high proportion of attacks directed at M. quadrifasciata, mainly due to this species remaining at the feeders while being bitten or returning to feeders immediately after being displaced. Very small (2-3 mm long) species likely remain competitive through a third strategy, insinuation (Johnson, 1983).
Insinuators fly away when threatened by dominant species but quickly return to nearby flowers and continue to feed.

\section{Natural context}

Aggressive and non-aggressive displacement also occurs on natural food sources. Abundance scans at a Dombeya wallichii tree at the Universidade de São Paulo, Ribeirão Preto revealed that $T$. hyalinata was numerically dominant, comprising $80 \%$ of bees counted (supplemental Table S3). This high abundance is somewhat surprising given the presence of over 30 honey bee colonies $<50 \mathrm{~m}$ away. Trigona hyalinata bit and aggressively removed other species from flowers $(0.08$ displacement interactions per observer-minute versus 0.52 at the feeder array). Trigona pallens and Tetragona clavipes are also known to exhibit low to medium intensity aggression at flowers (Roubik, 1980; pers. obs.), and Trigona cilipes low intensity aggression (Roubik, 1980). Trigona spinipes (Kerr, 1959), T. corvina and T. silvestriana (Johnson and Hubbell, 1974) will fight, sometimes to the death, at flowers.

Sugar-providing feeder arrays such as those typically used for bee dominance and aggression studies are somewhat unrealistic in that they are much smaller than massflowering trees, important food sources for stingless bees (Endress, 1994; Ramalho, 2004). Feeder arrays may elicit more intense interactions. However, they remain useful because they permit detailed data collection of species identity and behavior.

\section{Body size}

Our results do not support H2. Body size was not a major determinant of dominance. In our study, dominant species were medium-sized. However, unlike previous research (Johnson and Hubbell, 1974), we included the Melipona genus, whose species have a large and robust body form (Michener, 2007) but do not forage in large groups and are non-aggressive at food sources (Biesmeijer and Slaa, 2004). Dominance studies have typically overlooked Melipona, although this genus is commonly found in bee-plant interaction studies (Biesmeijer and Slaa, 2006).

\section{Aggression}

Our analyses suggest that aggression can mediate dominance but should not substitute as a measure of dominance. Rather, dominance should be interpreted as the suppression of one species by another (Keddy, 2001). This may arise from aggressive interactions, unequal resource exploitation efficiency or avoidance of a food source on which the dominant species is feeding. Analysis of data from Nagamitsu and Inoue (1997) also supports using ecologically relevant 
measures rather than aggression in assessing dominance. In their study, the most aggressively dominant species showed an average decrease in visitation in the presence of other species (supplemental Table S4).

\section{Dominance and group foraging}

Changes in dominance reported here and in other studies (Johnson and Hubbell, 1974; Nagamitsu and Inoue, 1997; Eltz et al., 2002; Slaa, 2003) suggest that food competition helps structure stingless bee communities. Feeding opportunities at individual resources increased with removal of group-foraging species. Group foragers typically gained control through aggression, suggesting they excel in interference competition. Solitary foragers exhibited behavioral flexibility, increasing visitation and marginally increasing local abundance in the absence of group foragers. This contradicts the prediction that foraging patterns of less aggressive species reflect floral preferences and will not be altered by removal of aggressive species (Johnson and Hubbell, 1975). Just as individuals may benefit competitively from larger body size in solitary bees (Bosch and Vicens, 2006), social bees may increase dominance with larger superorganism sizes: larger colonies whose workers forage in groups.

Acknowledgments We thank Felipe Contrera, Haley Hunter-Zinck, and Shawn Kessler for field assistance; Dr. Paulo Nogueira-Neto for kindly allowing us to work at the Fazenda Aretuzina; and Meg Eckles, David Holway, Brian Johnson, Peter Nonacs, Erin Wilson and anonymous referees for comments. A UCSD Chancellor's Fellowship (EML), an AWIS-SD Scholarship Award (EML), NSF IBN 0316697, NSF IBN 0545856, and Opportunities for Research in the Behavioral Sciences supported this research. This study complied with current laws of Brazil and the United States.

Open Access This article is distributed under the terms of the Creative Commons Attribution Noncommercial License which permits any noncommercial use, distribution, and reproduction in any medium, provided the original author(s) and source are credited.

\section{References}

Antonini Y. and Martins R.P. 2003. The value of a tree species (Caryocar brasiliense) for a stingless bee Melipona quadrifasciata quadrifasciata. J. Insect Conserv. 7: 167-174

Bednarz J.C. 1988. Cooperative hunting in Harris' hawks (Parabuteo unicinctus). Science 239: 1525-1527

Biesmeijer J.C. and Slaa E.J. 2004. Information flow and organization of stingless bee foraging. Apidologie 35: 143-157

Biesmeijer J.C. and Slaa E.J. 2006. The structure of eusocial bee assemblages in Brazil. Apidologie 37: 240-258

Bosch J. and Vicens N. 2006. Relationship between body size, provisioning rate, longevity and reproductive success in females of the solitary bee Osmia cornuta. Behav. Ecol. Sociobiol. 60: 26-33
Catlett R.H. 1961. An evaluation of methods for measuring fighting behaviour with special reference to Mus musculus. Anim. Behav. 9: $8-10$

Clark C.W. and Mangel M. 1984. Foraging and flocking strategies: information in an uncertain environment. Am. Nat. 123: 626-641

Cortopassi-Laurino M. and Ramalho M. 1988. Pollen harvest by Africanized Apis mellifera and Trigona spinipes in São Paulo: botanical and ecological views. Apidologie 19: 1-24

Dingemanse N.J. and de Goede P. 2004. The relation between dominance and exploratory behavior is context-dependent in wild great tits. Behav. Ecol. 15: 1023-1030

Dornhaus A. and Chittka L. 2004. Why do honey bees dance? Behav. Ecol. Sociobiol. 55: 395-401

Eccard J.A. and Ylönen H. 2003. Interspecific competition in small rodents: from populations to individuals. Evol. Ecol. 17: 423-440

Eltz T., Brühl C.A., van der Kaars S. and Linsenmair K.E. 2002. Determinants of stingless bee nest density in lowland dipterocarp forests of Sabah, Malaysia. Oecologia 131: 27-34

Eltz T., Brühl C.A., van der Kaars S., Chey V.K. and Linsenmair K.E. 2001. Pollen foraging and resource partitioning of stingless bees in relation to flowering dynamics in a Southeast Asian tropical rainforest. Insect. Soc. 48: 273-279

Endress P.K. 1994. Diversity and Evolutionary Biology of Tropical Flowers. Cambridge University Press, Cambridge. $511 \mathrm{pp}$

Fernández-Juricic E., Siller S. and Kacelnik A. 2004. Flock density, social foraging, and scanning: an experiment with starlings. Behav. Ecol. 15: 371-379

Heard T.A. 1999. The role of stingless bees in crop pollination. Annu. Rev. Entomol. 44: 183-206

Heithaus E.R. 1979. Community structure of neotropical flower visiting bees and wasps: diversity and phenology. Ecology 60: 190-202

Hilário S.D., Imperatriz-Fonseca V.L. and Kleinert A.d.M.P. 2000. Flight activity and colony strength in the stingless bee Melipona bicolor bicolor (Apidae, Meliponinae). Rev. Bras. Biol. 60: 299-306

Hölldobler B. and Wilson E.O. 1990. The Ants. Belknap Press of Harvard University Press, Cambridge, Massachusetts. 732 pp

Holway D.A. and Case T.J. 2001. Effects of colony-level variation on competitive ability in the invasive Argentine ant. Anim. Behav. 61: $1181-1192$

Howard J.J. 1985. Observations on resin collecting by six interacting species of stingless bees (Apidae, Meliponinae). J. Kans. Entomol. Soc. 58: 949-963

Hubbell S.P. and Johnson L.K. 1977. Competition and nest spacing in a tropical stingless bee community. Ecology 58: 949-963

Inouye D.W. 1978. Resource partitioning in bumblebees: experimental studies of foraging behavior. Ecology 59: 672-678

Jarau S., Hrncir M., Schmidt V.M., Zucchi R. and Barth F.G. 2003. Effectiveness of recruitment behavior in stingless bees (Apidae, Meliponini). Insect. Soc. 50: $365-374$

Johnson L.K. 1983. Foraging strategies and the structure of stingless bee communities in Costa Rica. Social insects in the tropics: Proc. 1st Int. Symp. I.U.S.S.I. and Soc. Mex. Entomol., Cocoyoc, Morelos, Mexico. pp 31-58

Johnson L.K. and Hubbell S.P. 1974. Aggression and competition among stingless bees: field studies. Ecology 55: 120-127

Johnson L.K. and Hubbell S.P. 1975. Contrasting foraging strategies and coexistence of two bee species on a single resource. Ecology 56: $1398-1406$

Keddy P.A. 2001. Competition (2nd edition). Kluwer Academic Publishers, Boston. $552 \mathrm{pp}$

Kerr W.E. 1959. Bionomy of meliponids-VI-aspects of food gathering and processing in some stingless bees. Symposium on Food Gathering Behavior of Hymenoptera, Ithaca, NY. pp 2-4

Kerr W.E. 1994. Communication among Melipona workers (Hymenoptera: Apidae). J. Insect Behav. 7: 123-128 
Kerr W.E. 1996. Biologia e Manejo da Tiúba: A abelha do Maranhão. EDUFMA, São Luís, Brazil. 156 pp

Lichtenberg E.M., Hrncir M. and Nieh J.C. 2009. A scientific note: foragers deposit attractive scent marks in a stingless bee that does not communicate food location. Apidologie 40: 1-2

Lindauer M. and Kerr W.E. 1960. Communication between the workers of stingless bees. Bee World 41: 29-71

Michener C.D. 2007. The Bees of the World. The Johns Hopkins University Press, Baltimore. 953 pp

Nagamitsu T. and Inoue T. 1997. Aggressive foraging of social bees as a mechanism of floral resource partitioning in an Asian tropical rainforest. Oecologia 110: 432-439

Nieh J.C. 2004. Recruitment communication in stingless bees (Hymenoptera, Apidae, Meliponini). Apidologie 35: 159-182

Nieh J.C., Contrera F.A.L. and Nogueira-Neto P. 2003. Pulsed massrecruitment by a stingless bee, Trigona hyalinata. Proc. R. Soc. B. 270: $2191-2196$

Nunes T.M., Nascimento F.S., Turatti I.C., Lopes N.P. and Zucchi R. 2008. Nestmate recognition in a stingless bee: does the similarity of chemical cues determine guard acceptance? Anim. Behav. 75: 1165-1171

Pedro S.R.M. and Camargo J.M.F. 2003. Meliponini neotropicais: o gênero Partamona Schwarz, 1939 (Hymenoptera, Apidae). Rev. Bras. Entomol. 47: 1-117

R Development Core Team. 2008. R: A language and environment for statistical computing. R Foundation for Statistical Computing, Vienna, Austria

Ramalho M. 1990. Foraging by stingless bees of the genus, Scaptotrigona (Apidae, Meliponinae). J. Apic. Res. 29: 61-67

Ramalho M. 2004. Stingless bees and mass flowering trees in the canopy of Atlantic Forest: a tight relationship. Acta Bot. Bras. 18: $37-47$

Reitz S.R. and Trumble J.T. 2002. Competitive displacement among insects and arachnids. Annu. Rev. Entomol. 47: 435-465

Roubik D.W. 1980. Foraging behavior of competing Africanized honeybees and stingless bees. Ecology 61: 836-845

Roubik D.W. 1983. Nest and colony characteristics of stingless bees from Panamá (Hymenoptera: Apidae). J. Kans. Entomol. Soc. 56: $327-355$

Roubik D.W. 1989. Ecology and Natural History of Tropical Bees. Cambridge University Press, Cambridge. $514 \mathrm{pp}$

Roubik D.W. and Villanueva-Gutiérrez R. 2009. Invasive Africanized honey bee impact on native solitary bees: a pollen resource and trap nest analysis. Biol. J. Linn. Soc. 98: 152-160

Schmidt V.M., Zucchi R. and Barth F.G. 2003. A stingless bee marks the feeding site in addition to the scent path (Scaptotrigona aff. depilis). Apidologie 34: 237-248
Schmidt V.M., Zucchi R. and Barth F.G. 2005. Scent marks left by Nannotrigona testaceicornis at the feeding site: cues rather than signals. Apidologie 36: 285-291

Schoener T.W. 1983. Field experiments on interspecific competition. Am. Nat. 122: 240-285

Schwarz H.F. 1948. Stingless bees (Meliponidae) of the Western Hemisphere. B. Am. Mus. Nat. Hist. 90: i-546

Slaa E.J. 2003. Foraging ecology of stingless bees: from individual behaviour to community ecology. $\mathrm{PhD}$ thesis, Utrecht University. $181 \mathrm{pp}$

Tóth E., Queller D.C., Dollin A. and Strassmann J.E. 2004. Conflict over male parentage in stingless bees. Insect. Soc. 51: 1-11

Traniello J.F.A. and Beshers S.N. 1991. Maximization of foraging efficiency and resource defense by group retrieval in the ant Formica schaufussi. Behav. Ecol. Sociobiol. 29: 283-289

van Nieuwstadt M.G.L. and Ruano Iraheta C.E. 1996. Relation between size and foraging range in stingless bees (Apidae, Meliponinae). Apidologie 27: 219-228

van Veen J.W., Sommeijer M.J. and Meeuwsen F. 1997. Behaviour of drones in Melipona (Apidae, Meliponinae). Insect. Soc. 44: 435447

von Frisch K. 1967. The Dance Language and Orientation of Bees. Belknap Press, Cambridge, Massachusetts. 566 pp

White F.J., Overdorff D.J., Keith-Lucas T., Rasmussen M.A., Kallam W.E. and Forward Z. 2007. Female dominance and feeding priority in a prosimian primate: experimental manipulation of feeding competition. Am. J. Primatol. 69: 295-304

Wille A. and Michener C.D. 1973. The nest architecture of stingless bees with special reference to those of Costa Rica (Hymenoptera: Apidae). Rev. Biol. Trop. 21: 1-278

Wilms W. and Wiechers B. 1997. Floral resource partitioning between native Melipona bees and the introduced Africanized honey bee in the Brazilian Atlantic rain forest. Apidologie 28: 339-355

Wilms W., Imperatriz-Fonseca V.L. and Engels W. 1996. Resource partitioning between highly eusocial bees and possible impact of the introduced Africanized honey bee on native stingless bees in the Brazilian Atlantic rainforest. Stud. Neotrop. Fauna E. 31: $137-151$

Wilson E.O. 1990. Success and dominance in Ecosystems: The Case of the Social Insects. Ecology Institute, Oldendorf/Luhe, Germany. $104 \mathrm{pp}$

Zar J.H. 1999. Biostatistical Analysis. Prentice-Hall, Upper Saddle River, NJ. 718 pp 